\title{
Propofol and remifentanil total intravenous anesthesia and the preservation of spontaneous respiration for a patient with mediastinal mass
}

\author{
Sung Kyu Rim, Yu Bin Son, Jong Il Kim, and Ji Heui Lee \\ Department of Anesthesiology and Pain Medicine, Korea Institute of Radiological and Medical Sciences, Seoul, Korea
}

A large mediastinal mass directly compressing the pulmonary arteries and the tracheobronchial trees may be associated with severe ventilation-perfusion $(\mathrm{V} / \mathrm{Q})$ mismatch. There have been some reports in the literature of sudden collapse involving mediastinal masses, possibly caused by the mass impinging on the pulmonary artery and the contralateral bronchus, causing hypoxemia and fatal V/Q mismatch while administrating general anesthesia [1]. In formulating an anesthetic plan for these patients, anesthesiologists should consider which anesthesia method will be least harmful on a case-by-case basis. This "NPIC" (noli pontes ignii consumere) anesthetic induction may be titrated infusion of intravenous anesthetics, preserving spontaneous respiration until the airway is definitively procured [2]. Herein, we report a case of anesthetic management during surgery to excise a mediastinal mass causing severe V/Q mismatch, in which total intravenous anesthesia (TIVA) without muscle relaxant, and the preservation of spontaneous respiration, were successfully used.

A 60-year-old woman was admitted to our hospital for dyspnea that had developed 1 year ago. A computed tomography scan of the chest revealed a large middle mediastinal tumor compressing the right pulmonary artery, left main bronchus, distal trachea and left atrium (Fig. 1). On arrival at the operating room, the patient had an initial $\mathrm{SpO}_{2}$ of $89 \%$ in the supine position. Sedation was induced with an initial effect-site concentration of $1.5 \mu \mathrm{g} / \mathrm{ml}$ of propofol and $0.5 \mathrm{ng} / \mathrm{ml}$ of remifentanil. A fiber optic bronchoscope loaded with a 37 French double lumen endobronchial tube (DLT) was introduced into the trachea. We could not advance the bronchoscope into the left main bronchus owing to severe narrowing of distal trachea and the left main bronchus. Therefore, we decided to place the endobronchial portion of the DLT at the right main bronchus. Following fiber optic intubation while the patient was conscious, propofol and remifentanil were gradually increased to effect-site concentrations of $2-3 \mu \mathrm{g} / \mathrm{ml}$ and $1-1.5 \mathrm{ng} / \mathrm{ml}$, respectively. The patient

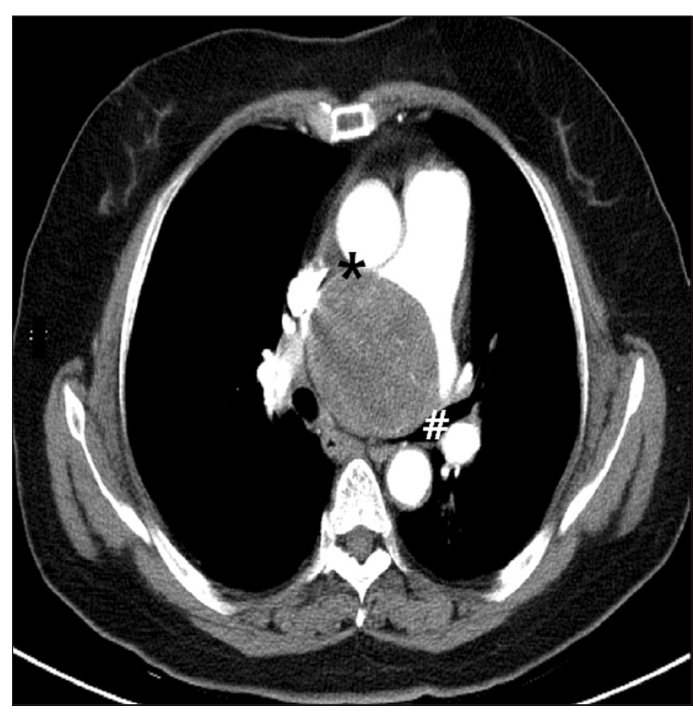

Fig. 1. Chest computed tomogram on admission shows a mass $(7.3 \mathrm{~cm}$ $\times 5.9 \mathrm{~cm} \times 6.1 \mathrm{~cm})$, located in the middle mediastinum, compressing the left main bronchus (\#), distal trachea, left atrium, and the right pulmonary artery $(*)$.

Corresponding author: Ji Heui Lee, M.D., Department of Anesthesiology and Pain Medicine, Korea Institute of Radiological and Medical Sciences, 215-4, Gongneung-dong, Nowon-gu, Seoul 139-706, Korea. Tel: 82-2-970-2820, Fax: 82-2-970-2413, E-mail: jiheui0255@naver.com (c) This is an open-access article distributed under the terms of the Creative Commons Attribution Non-Commercial License (http:// creativecommons.org/licenses/by-nc/3.0/), which permits unrestricted non-commercial use, distribution, and reproduction in any medium, provided the original work is properly cited. 
maintained spontaneous ventilation until the surgeon opened the thorax and could access the tumor. No muscle relaxant was used.

After the surgeon opened the right side of the thorax, facilitating access to the mass, the patient was mechanically ventilated with a tidal volume of $350 \mathrm{ml}$, and a respiratory rate of 18 breaths/min in response to the request from the surgeon for a low tidal volume. Single-lung ventilation could not be initiated because of high peak inspiratory pressure $(>28 \mathrm{mmHg}$ ) that was evident even when both lungs were mechanically ventilated. Anesthesia was maintained at an effect-site concentration of 3-5 $\mu \mathrm{g} / \mathrm{ml}$ for propofol and 3-5 $\mathrm{ng} / \mathrm{ml}$ for remifentanil, with $100 \%$ oxygen. Peak inspiratory pressure gradually decreased to $17 \mathrm{mmHg}$ as the surgeon slowly removed the mass. The entire surgery was completed without any adverse events, and vital signs remained stable throughout the procedure. The patient was transported to the intensive care unit in an intubated state, and breathing spontaneously. Having met the standard extubation criteria, she was extubated $2 \mathrm{~h}$ later. She was discharged on postoperative day 10 with significant improvement in her respiratory function. Histopathology revealed the tumor to be a schwannoma.

Patients with mediastinal masses are clinically challenging for the anesthesiologist. There are potential pathophysiological consequences associated with mediastinal masses, due to competition for mediastinal space with vital physiological structures. Anesthesia and associated interventions, such as neuromuscular blockade and positive pressure ventilation may result in adverse events in this context. The loss of spontaneous diaphragmatic movement associated with the paralysis induced by muscle relaxants reduces the normal transpleural pressure gradient, which contributes to distending the airways and maintaining patent airways [3]. This may induce a fatal near-total V/Q mismatch in a patient who already has an increased V/Q mismatch. There- fore, awake fiber optic intubation should be strongly considered, as should the maintenance of spontaneous ventilation while administrating general anesthesia until the airway is definitively procured; this is of the utmost importance in uncertain-risk or high-risk patients. In this case, we decided to proceed with awake intubation followed by general anesthesia using TIVA, which allowed for spontaneous ventilation until the surgeon could access the tumor. Target controlled infusion of propofol and remifentanil is particularly effective with regard to facilitating the transition from sedation for awake fiber optic intubation to complete anesthesia in preparation for surgery. Propofol is known to have less influence on neuromuscular function than volatile anesthetics. We did not measure neuromuscular function perioperatively. We decided that neuromuscular monitoring may not be of value with regard to the management of this patient while administrating TIVA without muscle relaxants.

Malherbe et al. [4] have investigated the use of TIVA and spontaneous respiration for airway endoscopy and surgery in children. In their study, the interaction between $\mathrm{CO}_{2}$ and the concentration of propofol or remifentanil at the brainstem or peripheral receptor determined the clinical respiration response. With a gradual increase in the propofol concentration administered via constant infusion, the slow onset of respiratory depression allowed the arterial $\mathrm{PCO}_{2}$ to rise and spontaneous respiration was maintained as a result of this respiratory stimulation arising from the increased $\mathrm{PaCO}_{2}$. When propofol is given slowly, spontaneous respiration is maintained although predicted blood concentrations are measured in excess of $3 \mu \mathrm{g} / \mathrm{ml}$ [5].

We conclude that maintaining spontaneous ventilation with TIVA as an anesthetic technique, thus avoiding the use of muscle relaxants, may reduce the risk of severe V/Q mismatch in the anesthetic management of uncertain-risk patients with mediastinal mass, in which life-threatening cardiopulmonary collapse may occur as a result of anesthesia.

\section{References}

1. Huang YL, Yang MC, Huang CH, Wang CC, Wu ET, Huang SC, et al. Rescue of cardiopulmonary collapse in anterior mediastinal tumor: case presentation and review of literature. Pediatr Emerg Care 2010; 26: 296-8.

2. Frawley G, Low J, Brown TC. Anaesthesia for an anterior mediastinal mass with ketamine and midazolam infusion. Anaesth Intensive Care 1995; 23: 610-2.

3. Neuman GG, Weingarten AE, Abramowitz RM, Kushins LG, Abramson AL, Ladner W. The anesthetic management of the patient with an anterior mediastinal mass. Anesthesiology 1984; 60: 144-7.

4. Malherbe S, Whyte S, Singh P, Amari E, King A, Ansermino JM. Total intravenous anesthesia and spontaneous respiration for airway endoscopy in children-a prospective evaluation. Pediatr Anaesth 2010; 20: 434-8.

5. Bouillon T, Bruhn J, Radu-Radulescu L, Andresen C, Cohane C, Shafer SL. Mixed-effects modeling of the intrinsic ventilatory depressant potency of propofol in the non-steady state. Anesthesiology 2004; 100: 240-50. 